\title{
Evaluation of the Antioxidant Activity of Ethanolic Extracts of Some Varieties of Onion
}

\section{María del Carmen Gutiérrez, Patricia Della Rocca, Elizabeth Graciela De Seta, Fernando Reina}

Chemical Engineering Department, Buenos Aires Regional Faculty, National Technological University, Ciudad Autónoma de Buenos Aires, Argentina.

Email: info@quimica.frba.utn.edu.ar

Received September $4^{\text {th }}, 2013$; revised October $4^{\text {th }}, 2013$; accepted October $11^{\text {th }}, 2013$

Copyright (C) 2013 María del Carmen Gutiérrez et al. This is an open access article distributed under the Creative Commons Attribution License, which permits unrestricted use, distribution, and reproduction in any medium, provided the original work is properly cited. In accordance of the Creative Commons Attribution License all Copyrights (C) 2013 are reserved for SCIRP and the owner of the intellectual property María del Carmen Gutiérrez et al. All Copyright (C) 2013 are guarded by law and by SCIRP as a guardian.

\begin{abstract}
The content of polyphenolic in commercial onions has been determined. The antioxidant activity of their ethanolic extracts, as well as their effects on the oxidation of edible corn oil during accelerated ageing, was studied. Maceration of taxonomically identified commercial vegetable samples, previously peeled and thinly sliced, was carried out at ambient temperature, out of direct light, with occasional agitation and ultrasound, employing $95 \%$ ethyl alcohol as the extraction solvent, allowing them to stand for 7 days. The total polyphenolic contents were determined on the filtrated extracts using the Folin-Ciocalteau method. The antioxidant activity was evaluated on emulsions of ethanolic extracts of onion prepared in edible commercial corn oil, using sorbitan monooleate as emulsifying agent. The peroxide values were analyzed using the iodometric method; oxidation induction times were obtained from the peroxide evolution graphs, using the tangent method. Oil samples emulsified with ethanolic onion extracts showed an extension of the induction period. A 7 day ageing study at $45^{\circ} \mathrm{C}$ was additionally performed to determine the conjugated dienes on pure commercial corn oil and its emulsions by visible spectrophotometry. The spectral analysis showed an increase of the measured absorbances in oil samples without additives and no change for the oils emulsified with onion extract. An increasing of diene values was observed for corn oil without additives during ageing; no changes in the value were observed in oils emulsified with onion extracts.
\end{abstract}

Keywords: Onion; Antioxidant Activity; Polyphenolic; Ethanolic Extracts; Emulsified Oil

\section{Introduction}

Epidemiologic studies have determined that the consumption of vegetables and fruit is related to the reduction of the risks of contracting a cardiovascular disease or cancer.

Foods containing significant amounts of bioactive components may provide desirable health benefits and play important roles in the prevention of chronic diseases [1].

At present we pay the interest in the biological effects of phenolic compounds as it was found that diets rich in fruits and vegetables appear to protect against cardiovascular disease [2,3] and some forms of cancer [4]. Currently there is an increasing preference for the use of natural antioxidants [5] although many of them have been used since antiquity. Many plant extracts have demonstrated considerable stabilizing effect against lipid oxidation reactions and, consequently, they can have significant commercial potential as source of nutraceutical or functional food ingredients [6]. Antioxidants with an important activity have been found in berries [7], cherries [8], citrics [9], kiwis [10], olives [11], cocoa [12], potatoes [13], tomatoes [14], garlics [15], onions [16] and soybeans [17]. Most of the spices, e.g. red pepper [18], ginger [19] and rosemary [20] also have relevant antioxidant properties.

Onion is proposed as a viable source of phenolic compounds and flavonoids. Studies conducted over different cultivars demonstrate that total oxidant activity is lower in white onion varieties; red varieties have a 100 $\mathrm{mg} / 100 \mathrm{~g}$ average content of gallic acid equivalents [21]. The essential oil reveals interesting properties, such as 
antimicrobial agent and moderate reducing power feasible to implement in food [22]. Also, phenolic extracts obtained from wastes of onion were used to evaluate the capacity inhibiting of processes inflammatory and oxidation of low-density lipoprotein (LDL) [23].

Likewise, different methods of extraction of the active components have been used for their assessment, resulting in variations of the reported activities [24,25]. When extraction is carried out by the method of microwaveassisted greater efficiency is obtained with higher antioxidant activities [26].

Antioxidant capacity scores were reported [27] from the oxygen radical absorption capacity measurements (ORAC).

Most investigations have been dedicated to quantifying polyphenols and its antioxidant capacity. Despite the results achieved, further studies should be performed in order to enhance the knowledge about extraction and identification of active components present in less studied vegetables.

The efficiency of extraction of natural antioxidants (NAO) depends on the fraction, the type of vegetable used, and the ability of the active components to provide sufficient antioxidant capacity. Therefore a simple method of extraction of polyphenolic components from commercial onions has been developed by the authors, in order to evaluate their performance as an alternative source of natural antioxidants.

\section{Materials and Methods}

\subsection{Plant Material}

White onion taxonomically identified as Allium cepa, provided by the National Institute of Agricultural Technology (I.N.T.A. Mendoza) and commercial white onion purchased in local grocery store. Bulbs from each variety were stored at $4^{\circ} \mathrm{C}$ until sampling.

\subsection{Sample Preparation}

Bulbs were randomly selected for extraction. Onions were peeled, eliminating the skin and the first and second layers, and chopped in fine pieces.

\subsection{Extraction}

Maceration was performed at room temperature, out of direct light, with occasional agitation and ultrasound (to facilitate extraction) of an exactly weighed sample quantity, using 99.5\%-absolute-pro analysis ACS ethyl alcohol as extraction solvent, in a 50\% concentration (in masses), allowing them to stand for 7 days. Ethanolic extracts were filtered using glass wool and diluted 10:1 with $80 \%$ ethanol to a total of $5 \mathrm{~cm}^{3}$.

\subsection{Spectrophotometric Analysis}

Absorbance (AU) readings were made in triplicate using: Shimadzu series UV1700 Spectrophotometer Quartz Cuvettes of $1.0 \mathrm{~cm}$ thickness. Wavelengths $(\lambda)$ :

- Determination of Total Polyphenol at $765 \mathrm{~nm}$.

- Determination of Conjugated Dienes at $233 \mathrm{~nm}$.

- Determination of Conjugated Trienes at $268 \mathrm{~nm}$ and $278 \mathrm{~nm}$.

\subsection{Determination of Total Polyphenols}

Spectrophotometric determination of Total Polyphenol (PFT), at $765 \mathrm{~nm}$, in the extracts obtained was performed using the Folin-Ciocalteu method, based on the Singleton and Rossi (1965) procedures and modified by Waterhouse (2001).

Determinations were carried out, both for the classified and for the commercial onion samples. Concentrations of polyphenols in sample extract were calculated by linear regression onto the standard curve of monohydrated gallic acid, ACS analytic reagent, as standard.

Three parallel determinations of each sample were performed. The average values and their standard deviations were calculated

\subsection{Determination of Peroxide Value}

The peroxide values (PV) were analyzed by the iodometric method, employing p.a. ACS potassium iodide solution, analytic reagent ACS sodium thiosulfate pentahydrate for the preparation of the titrating solution, pro analysis trichloromethane (chloroform) and soluble starch as indicator, according to the American Oil Chemists' Society AOAC Official Method 942.27 [28].

Iodine is liberated by hydroperoxides in the oil in presence of excess iodide in a stoichiometric ratio. The amount of iodine present is determined by titration with a standard sodium thiosulfate solution using a starch indicator, thereby reflecting how much peroxide is present in the oil or lipid extract.

Three parallel determinations of each sample were carried out. The average values and their standard deviations were calculated.

\subsection{Antioxidant Capacity}

Emulsions of ethanolic extract of onion were prepared in $10 \%$ concentration (in masses) in edible commercial corn oil with composition of $51 \mathrm{~g} / 100 \mathrm{~g}$ polyunsaturated fat and vitamin E (25 mg/100g of oil) using sorbitan monooleate (SPAN 80 ) in a concentration of $1 \% \mathrm{~m} / \mathrm{m}$ as emulsifying agent.

A sample of the same commercial corn oil without additives was used as blank; a corn oil sample with a syn- 
thetic antioxidant (butylhydroxytoluene) added, in $0.01 \%$ concentration (in masses) was also prepared for comparison.

The samples were stored for 45 days on a heater at $45^{\circ} \mathrm{C}$ temperature and protected from direct light, with occasional agitation. With the PV results, the evolution of the $\mathrm{mEq} \mathrm{O}_{2} / \mathrm{kg}$ generated in the oxidation process was recorded as function of the storage time. For each of the samples under study, oxidation induction times were determined from the charts by the tangents method.

\subsection{Conjugated Dienes Assay}

A 7 day ageing study, at a temperature of $45^{\circ} \mathrm{C}$, was additionally performed to determine primary lipid oxidation products: Conjugated Dienes were determined on both the pure commercial corn oil and the samples of the emulsions of ethanolic onion extract in edible corn oil, by UV-Visible spectrophotometry, measuring the absorbances at $233 \mathrm{~nm}, 268 \mathrm{~nm}$ and $278 \mathrm{~nm}$ and 2.2.4trimethylpentane (Isooctane) for chromatographic use, as a sample preparation solvent, as described in Current Protocols in Food Analytical Chemistry (2001) D21.1D2.1.15 [29].

The absorbance, measured at 233 and $268 \mathrm{~nm}$, was employed to monitor the formation of conjugated dienes (CDs) and trienes (CTs) of polyunsaturated fatty acids (PUFAs), respectively. Increasing absorption values are an indication that oxidation is proceeding. The $\mathrm{CD}$ moiety is a strong UV-absorbing chromophore that can be spectrophotometrically detected. When present in fatty acids, the CD moiety shows an absorption in the UV region at $233 \mathrm{~nm}$ and stands out as a distinct peak. When PUFAs containing three or more double bonds (e.g., linolenic acid) undergo oxidation, the conjugation of $\mathrm{CD}$ moieties can be extended to include another double bond resulting in the formation of a conjugated triene (CT). CTs absorb radiation in the UV region like CDs, but show three signature absorption bands. The main peak is at $268 \mathrm{~nm}$; there is also a secondary peak at $278 \mathrm{~nm}$.

From the results obtained the concentration of conjugated dienes $[\mathrm{CD}]$ was calculated as follows:

$$
[\mathrm{CD}]=\frac{A}{\varepsilon \times l}
$$

where

$A=$ Absorbance at $233 \mathrm{~nm}$.

$\varepsilon=2.525 \times 10^{4} \mathrm{M}^{-1} \cdot \mathrm{cm}^{-1}=$ Molar absorptivity of Linoleic Acid Hydroperoxide.

$l=$ Optical path of the cuvette $1 \mathrm{~cm}$.

And the conjugated diene value ( $\mathrm{CD}$ value):

$$
\mathrm{CD}_{\text {value }}=\frac{[\mathrm{CD}] \times 2.5 \times 10^{4}}{m}
$$

where:

$$
\begin{aligned}
& 2.5 \times 10^{4} \text { is the correction factor. } \\
& m=\text { mass of the sample }(\mathrm{g}) .
\end{aligned}
$$

\section{Results and Discussion}

\subsection{Total Polyphenols}

The calibration curve obtained, using gallic acid as external standard, corresponds to a first-order equation, and

$$
y=0.006 x+0.027
$$

with correlation coefficient $R^{2}=0.9975$.

The taxonomically identified onion extract has a total polyphenol concentration of $(323 \pm 18) \mathrm{mg} / \mathrm{dm}^{3}$, being slightly higher than that corresponding to the commercial onion extract $(310 \pm 18) \mathrm{mg} / \mathrm{dm}^{3}$.

\subsection{Peroxide Values}

The values obtained for peroxide values $(\mathrm{PV}$ in $\mathrm{mEq}$ $\mathrm{O}_{2} / \mathrm{kg}$ ) at different storage times for the samples analyzed are shown in Table 1.

Figure 1 shows the evolution of the Peroxide Values.

Table 1. Peroxide values of the samples analyzed at different storage times.

\begin{tabular}{ccccc}
\hline $\begin{array}{c}\text { Time } \\
\text { (days) }\end{array}$ & $\begin{array}{c}\mathrm{PV} \mathrm{(1)} \\
\left(\mathrm{mEq} \mathrm{O}_{2} / \mathrm{kg}\right)\end{array}$ & $\begin{array}{c}\mathrm{PV}(2) \\
\left(\mathrm{mEq} \mathrm{O}_{2} / \mathrm{kg}\right)\end{array}$ & $\begin{array}{c}\mathrm{PV}(3) \\
\left(\mathrm{mEq} \mathrm{O}_{2} / \mathrm{kg}\right)\end{array}$ & $\begin{array}{c}\mathrm{PV}(4) \\
\left(\mathrm{mEq} \mathrm{O}_{2} / \mathrm{kg}\right)\end{array}$ \\
\hline 5 & $1.7 \pm 0.1$ & $1.5 \pm 0.1$ & $1.9 \pm 0.1$ & $1.6 \pm 0.1$ \\
12 & $4.2 \pm 0.1$ & $2.1 \pm 0.1$ & $1.6 \pm 0.1$ & $3.4 \pm 0.1$ \\
19 & $3.5 \pm 0.1$ & $3.1 \pm 0.1$ & $2.9 \pm 0.1$ & $2.0 \pm 0.1$ \\
24 & $12.4 \pm 0.1$ & $12.7 \pm 0.1$ & $18.1 \pm 0.1$ & $22.7 \pm 0.1$ \\
33 & $14.9 \pm 0.1$ & $18.2 \pm 0.1$ & $34.1 \pm 0.2$ & $53.6 \pm 0.2$ \\
40 & $17.4 \pm 0.1$ & $22.9 \pm 0.2$ & $46.9 \pm 0.2$ & $92.0 \pm 0.2$ \\
47 & $27.0 \pm 0.2$ & $26.9 \pm 0.2$ & $48.9 \pm 0.2$ & $100.1 \pm 0.2$ \\
\hline
\end{tabular}

References: (1) Edible oil with aggregated ethanolic extract of commercial Allium cepa. (2) Edible oil with aggregated ethanolic extract of Allium cepa classified. (3) Edible oil with aggregated Butylhydroxytoluene. (4) Edible oil without antioxidant aggregate.

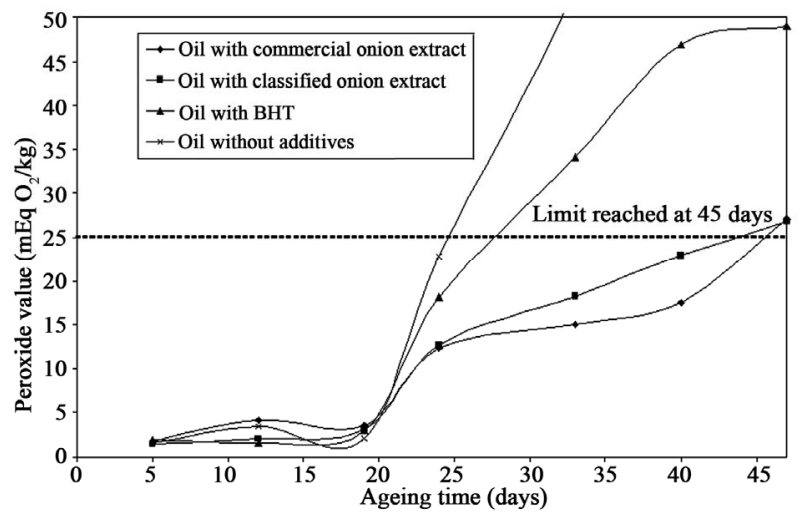

Figure 1. Evolution of the peroxide values. 
It can be seen that the peroxide value for emulsified oils with ethanol extracts of onion, after forty-five days of ageing, is $25 \mathrm{mEq} \mathrm{O}_{2} / \mathrm{kg}$. In comparison, the oil samples without additive and with butylhydroxytoluene reached that value in less time.

Figure 2 shows the time in which the maximum limit accepted by the Argentinean Food Code (CAA), $10 \mathrm{mEq}$ $\mathrm{O}_{2} / \mathrm{kg}$ is reached.

An increase of the induction period can be observed in the oil samples emulsified with ethanolic onion extract, including those classified as commercial, as well as a delay of the time in which peroxides reach the limit established by the Argentinean Food Code (CAA), $10 \mathrm{mEq}$ $\mathrm{O}_{2} / \mathrm{kg}$, in the kinetic curves of peroxide accumulation, thus demonstrating a net antioxidant effect produced by the polyphenolic contents present in the onion extracts.

Figures 3-5 show the kinetics curves peroxide accumulation, which were used to determine the induction times. The results were: 17, 17.5 and 19.5 days, respectively, for pure corn oil, oil with addition of butylhydroxytoluene and oil emulsified with ethanolic onion extract.

Oxidation induction times were determined from the charts by the tangents method.

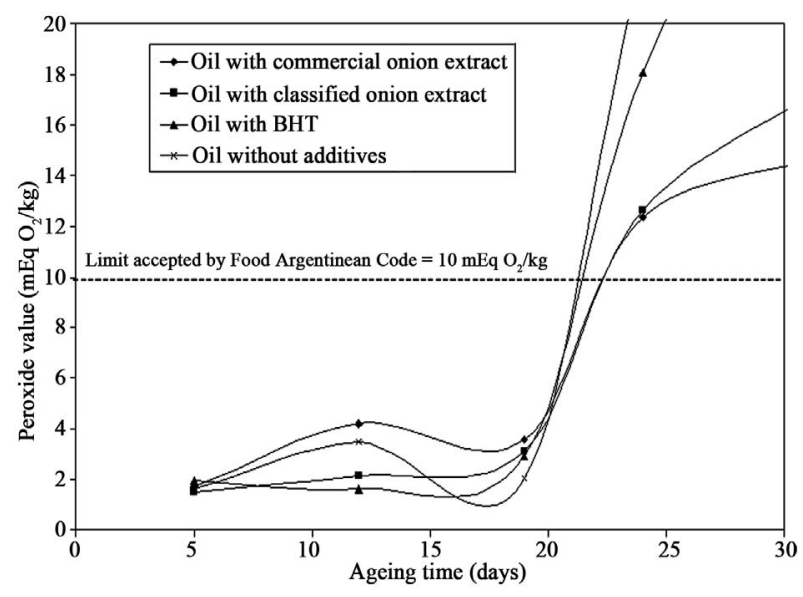

Figure 2. Evolution of the peroxide values.

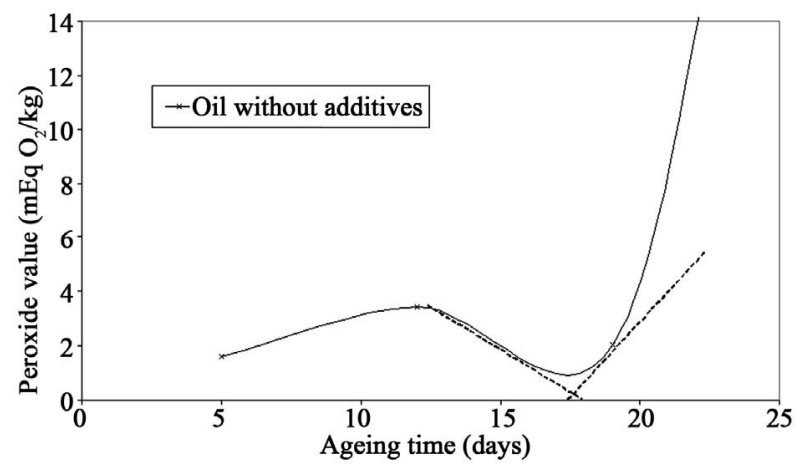

Figure 3. Evolution of the peroxide value for corn oil without aggregates.

\subsection{Spectral Analysis by Means of UV-Visible Spectrophotometry and Determination of Conjugated Dienes}

Figures 6 and 7 show the spectral analysis, which reveals an increase of the absorbancies measured for the oil samples without additives and no modification for the oils emulsified with onion extracts. The information obtained is presented on Tables 2 and 3.

Results obtained for the concentration of conjugated dienes were $9.02 \times 10^{-6} \mathrm{mmol} / \mathrm{cm}^{3}$ for the corn oil with-

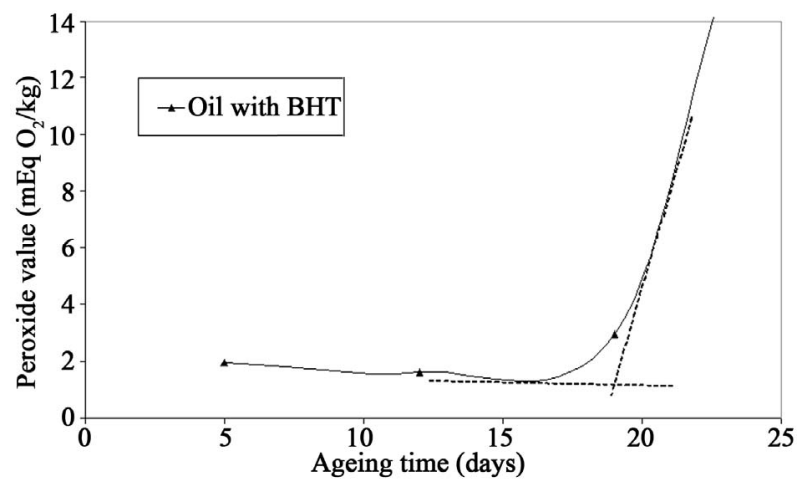

Figure 4. Evolution of the peroxide value for corn oil with BHT.

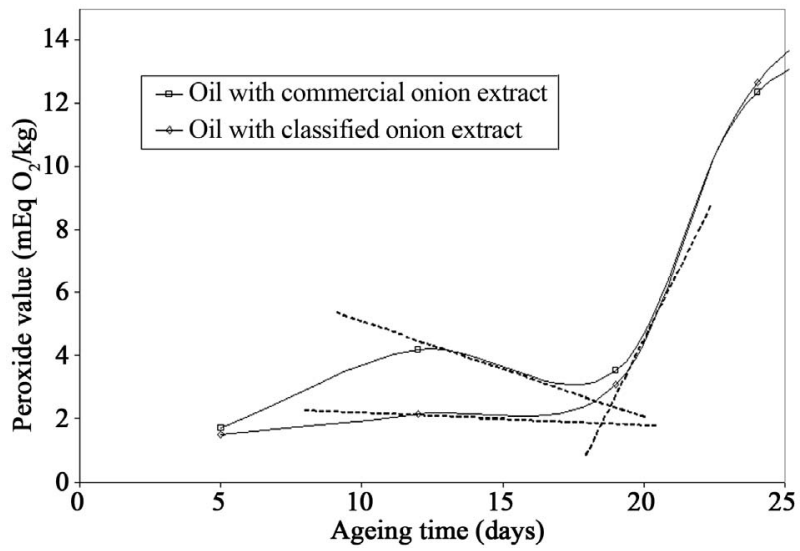

Figure 5. Peroxide value evolution over time for emulsion obtained from the Allium cepa extracts in corn oil.

Table 2. Sample absorbancies obtained at day 1.

\begin{tabular}{ccccc}
\hline Samples & Mass (g) & Abs 233 nm & Abs 268 nm & Abs 278 nm \\
\hline Pure oil & 0.018 & $0.228 \pm 0.001$ & $0.052 \pm 0.001$ & $0.046 \pm 0.001$ \\
Oil + extract & 0.019 & $0.294 \pm 0.001$ & $0.078 \pm 0.001$ & $0.071 \pm 0.001$
\end{tabular}

Table 3. Sample absorbancies obtained at day 7.

\begin{tabular}{ccccc}
\hline Samples & Mass $(\mathrm{g})$ & Abs 233 nm & Abs 268 nm & Abs 278 nm \\
\hline Pure oil & 0.0155 & $0.347 \pm 0.001$ & $0.066 \pm 0.001$ & $0.059 \pm 0.001$ \\
Oil + extract & 0.0186 & $0.288 \pm 0.001$ & $0.059 \pm 0.001$ & $0.053 \pm 0.001$
\end{tabular}




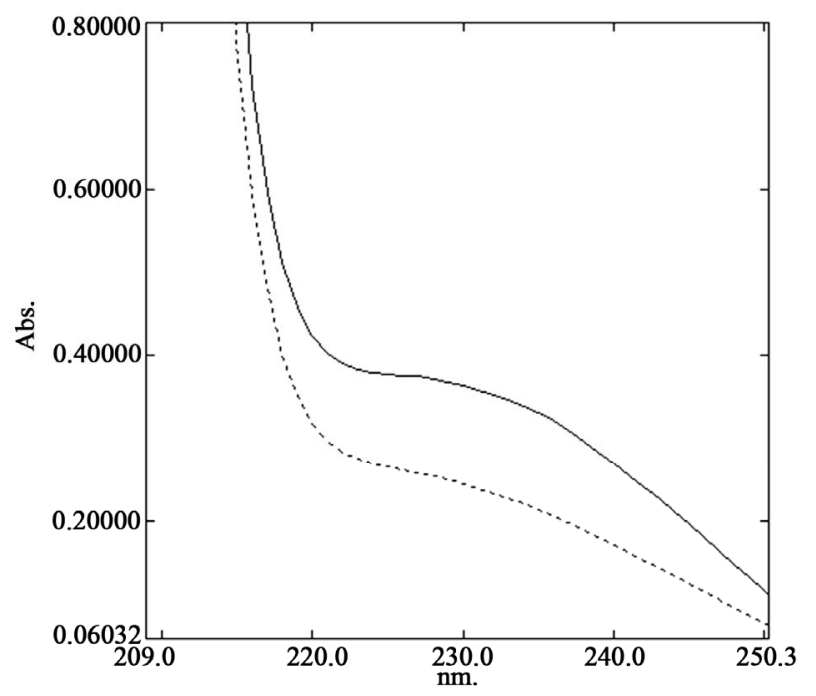

Figure 6. UV-Visible spectrophotometry for corn oil without antioxidant aggregates in its initial state (dotted line spectrophotometry) and after 7 days at a temperature of $45^{\circ} \mathrm{C}$ (continuous line spectrophotometry).

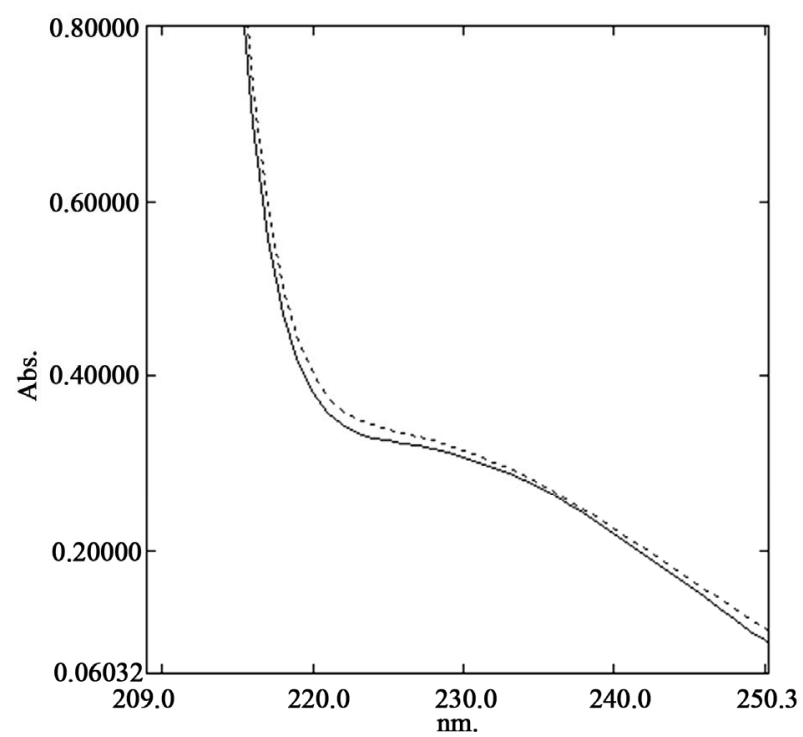

Figure 7. UV-visible spectrophotometry for the emulsions of ethanolic extracts of onion $(10 \% \mathrm{~m} / \mathrm{m})$ in commercial corn oil, in its initial state (dotted line spectrophotometry) and after 7 days elapsed at a temperature of $45^{\circ} \mathrm{C}$ (continuous line spectrophotometry).

out additives at the beginning of the experiment, rising to $1.37 \times 10^{-5} \mathrm{mmol} / \mathrm{cm}^{3}$ on the 7 th day of ageing, corresponding to a dienes index of $12.5 \mathrm{mmol} / \mathrm{g}$ and 22.2 $\mathrm{mmol} / \mathrm{g}$ respectively.

On the other hand, the oils emulsified with onion extracts presented a concentration of conjugated dienes of $1.16 \times 10^{-5} \mathrm{mmol} / \mathrm{cm}^{3}$ in the initial level and $1.14 \times 10^{-5}$ $\mathrm{mmol} / \mathrm{cm}^{3}$ on the 7 th day. The conjugated dienes indexes were $14.9 \mu \mathrm{mol} / \mathrm{g}$ and $15.3 \mu \mathrm{mol} / \mathrm{g}$ respectively.

Data shows the increase of concentration of conju- gated dienes in the oil without antioxidants. Likewise no increase was found on oil samples with ethanolic onion extracts. Thus was demonstrated the antioxidant capacity of polyphenols extracted from some varieties of onion.

\section{Conclusions}

The results obtained suggest that commercial onions have a considerable content of polyphenols. These facts lead to the conclusion that the addition of ethanol extracts of onion commercial to corn oil prolongs oxidation induction time and also generates a decrease in the concentration of conjugated dienes in ageing period, which show the antioxidant power of the polyphenols present.

The use of commercial onions as sources to obtain polyphenolic substances and their applications as antioxidant additives can be considered entirely viable.

\section{Acknowledgements}

This research was funded by National Technological University, Buenos Aires Regional Faculty.

The authors thank Dr. Isaac Marcos Cohen for his valuable contribution.

\section{REFERENCES}

[1] R. H. Liu, "Health Benefits of Fruit and Vegetables Are from Additive and Synergistic Combinations of Phytochemicals," American Journal of Clinical Nutrition, Vol. 78, No. 3, pp. 517S-520S.

[2] G. Block and L. Langseth, "Antioxidant Vitamins and Disease Prevention," Food Technology, 1994, pp. 80-84.

[3] M. G. L. Hertog, E. J. M. Feskens, P. C. H. Hollman, M. B. Katan and D. Kromhout, "Dietary Antioxidant Flavonoids and Risk of Coronary Heart Disease, The Zutphen Elderly Study," The Lancet, Vol. 342, No. 8878, 1993, pp. 1007-1011. http://dx.doi.org/10.1016/0140-6736(93)92876-U

[4] J. Pokorny, N. Yanishlieva and M. Gordon, "Antioxidants in Food. Practical Applications," Woodhead Publishing Limited, Abington Hall, Abington, 2001.

[5] G. Block, "A Role for Antioxidants in Reducing Cancer Risk," Nutrition Review, Vol. 50, No. 7, 1992, pp. $207-$ 213.

http://dx.doi.org/10.1111/j.1753-4887.1992.tb01329.x

[6] G. Shui and L. Leong, "Residue from Star Fruit as Valuable Source for Functional Food Ingredients and Antioxidant Nutraceuticals," Food Chemistry, Vol. 97, No. 2, 2006, pp. 277-284.

http://dx.doi.org/10.1016/j.foodchem.2005.03.048

[7] P. Abuja, M. Murkovic and W. Pfanhauser, "Antioxidant and Prooxidant Activities of Eldeberry (Sambucus nigra) Extract in Low Density Lipoprotein Oxidation," Journal of Agricultural and Food Chemistry, Vol. 46, No. 10, 1998, pp. 4091-4096. http://dx.doi.org/10.1021/jf980296g

[8] H. Wang, Muraleedharan, M. G. Nair, G. M. Strasburg, Y. 
Chang, A. M. Booren, I. J. Gray and D. L. DeWitt, “Antioxidant and Antiinflammatory Activities of Anthocyanins and Their Aglycon, Cyanidin, from Tart Cherries," Journal of Natural Products, Vol. 62, No. 2, 1999, pp. 294-296. http://dx.doi.org/10.1021/np980501m

[9] M. Saleh, F. A. Hashem and K. W. Glombitza, "Study of Citrus Taitensis and Radical Scavenger Activity of the Flavonoids Isolated," Food Chemistry, Vol. 63, No. 3, 1998, pp. 397-400. http://dx.doi.org/10.1016/S0308-8146(97)00238-0

[10] H. M. Dawes and J. B. Keene, "Phenolic Composition of Kiwi Fruit Juice," Journal of Agricultural and Food Chemistry, Vol. 47, No. 6, 1999, pp. 2398-2403. http://dx.doi.org/10.1021/jf9810261

[11] A. Romani, N. Mulinacci, P. Pinelli, F. Vincieri and A. Cimato, "Polyphenolic Content in Five Tuscany Cultivars of Olea europaea L.," Journal of Agricultural and Food Chemistry, Vol. 47, No. 3, 1999, pp. 964-967. http://dx.doi.org/10.1021/jf980264t

[12] C. Sanbongi, N. Osakabe, M. Natsume, T. Takizawa, S. Gomi and T. Osawa, "Antioxidative Polyphenols Isolated from Theobroma cacao," Journal of Agricultural and Food Chemistry, Vol. 46, No. 2, 1998, pp. 454-457. http://dx.doi.org/10.1021/jf970575o

[13] M. Friedman, "Chemistry, Biochemistry, and Dietary Role of Potato Polyphenols. A Review," Journal of Agricultural and Food Chemistry, Vol. 45, No. 5, 1997, pp. 1523-1540. http://dx.doi.org/10.1021/jf960900s

[14] A. Abushita, E. Hebshi and P. Biacs, "Determination of Antioxidant Vitamins in Tomatoes," Food Chemistry, Vol. 60, No. 2, 1997, pp. 207-212. http://dx.doi.org/10.1016/S0308-8146(96)00321-4

[15] O. I. Aruoma, J. Spencer, D. Warren, P. Jenner, J. Butler and B. Halliwell, "Characterization of Food Antioxidants, Illustrated Using Commercial Garlic and Ginger Preparations," Food Chemistry, Vol. 60, No. 2, 1997, pp. 149156. http://dx.doi.org/10.1016/S0308-8146(95)00254-5

[16] J. Lachman, A. Pronek, A. Hejtmánkova, J. Dudjak, V. Pivec and K. Faitová, "Total Polyphenol and Main Flavonoid Antioxidants in Different Onion (Allium cepa L.) Varieties," Czech University of Agriculture, Faculty of Agriculture, Prague, 2003.

[17] C. Ganthavorn and J. S. Hughes, "Inhibition of Soybean Oil Oxidation by Extracts of Dry Beans (Phaseolus vulgaris)," Journal of the American Oil Chemists' Society, Vol. 74, No. 8, 1997, pp. 1025-1030. http://dx.doi.org/10.1007/s11746-997-0020-5

[18] F. Markus, H. Daood, J. Kapitany and P. A. Biacs, "Change in the Carotenoid and Antioxidant Content of Spice Red Pepper (Paprika) as a Function of Ripening and Some Technological Factors," Journal of Agricultural and Food Chemistry, Vol. 47, No. 1, 1999, pp. 100-

\section{7. http://dx.doi.org/10.1021/jf980485z}

[19] H. Kikuzaki and N. Nakatani, "Antioxidant Effects of Ginger Constituents," Journal of Food Science, Vol. 58, No. 6, 1993, pp. 1407-1410. http://dx.doi.org/10.1111/j.1365-2621.1993.tb06194.x

[20] C. Hall and S. Cuppett, "The Hydrogen Donating Mechanism of Rosmariquinone," American Oil Chemist's Society 88th Annual Meeting and Exposition, Seattle, 11-14 May 1997, Section 37 General Lipid Oxidation and Quality I.

[21] Ch. Kaur, S. Joshi and H. C. Kapoor, "Antioxidants in Onion (Allium cepa L) Cultivars Grown in India," Journal of Food Biochemistry, Vol. 33, No. 2, 2009, pp. 184200. http://dx.doi.org/10.1111/j.1745-4514.2009.00212.x

[22] C.-L. Ye, D.-H. Dai and W.-L. Hu, "Antimicrobial and Antioxidant Activities of the Essential Oil from Onion (Allium cepa L.)," Food Control, Vol. 30, No. 1, 2013, pp 48-53. http://dx.doi.org/10.1016/j.foodcont.2012.07.033

[23] T. Albishi, J. A. John, A. S. Al-Khalifa and F. Shahidi, "Antioxidant, Anti-Inflammatory and DNA Scission Inhibitory Activities of Phenolic Compounds in Selected Onion and Potato Varieties," Journal of Functional Foods, Vol. 5, No. 2, 2013, pp. 930-939. http://dx.doi.org/10.1016/j.jff.2013.02.005

[24] I. Budic-Leto, T. Lovri, I. Pezo and J. Gajdo Kljusuri, "Study of Dynamics of Polyphenol Extraction during Traditional and Advanced Maceration Processes of the Babic Grape Variety," Food Technology and Biotechnology, Vol. 43, No. 1, 2005, pp. 47-53.

[25] H. Nawaz, J. Shi, G. S. Mittal and Y. Kakudac, "Extraction of Polyphenols from Grape Seedsand Concentration by Ultrafiltration," Separation and Purification Technology, Vol. 48, No. 2, 2006, pp. 176-181. http://dx.doi.org/10.1016/j.seppur.2005.07.006

[26] Zill-e-Huma, M. Albert-Vian, A.-S. Fabiano-Tixier, M. Elmaataoui, O. Dangles and F. Chemat, "A Remarkable Influence of Microwave Extraction: Enhancement of Antioxidant Activity of Extracted Onion Varieties," Food Chemistry, Vol. 127, No. 4, 2011, pp. 1472-1480. http://dx.doi.org/10.1016/j.foodchem.2011.01.112

[27] G. Cao, E. Sofic and R. L. Prior, "Antioxidant Capacity of Tea and Common Vegetables," Journal of Agricultural and Food Chemistry, Vol. 44, No. 11, 1996, pp. 34263431. http://dx.doi.org/10.1021/j19602535

[28] AOCS (American Oil Chemists' Society), "Official Method Cd 8-53. Peroxide Value,” In: D. Firestone, Ed., Official Methods and Recommended Practices of the American Oil Chemists' Society, 5th Edition, AOCS, Champaign, 1998.

[29] "Current Protocols in Food Analytical Chemistry," John Wiley \& Sons, Inc., 2001, D2.1.1-D2.1.15. 